\title{
EFEKTIVITAS PENGGUNAAN APLIKASI PEMBELAJARAN BERBASIS MOBILE SMARTPHONE SEBAGAI MEDIA PENGENALAN SEJARAH LOKAL MASA REVOLUSI FISIK DI KALIMANTAN SELATAN PADA SISWA SEKOLAH MENENGAH ATAS
}

\author{
Helmi Akmal \\ Program Studi Pendidikan Sejarah, FKIP Universitas Lambung Mangkurat, Banjarmasin \\ E-mail: helmiakmal47@ulm.ac.id \\ Heri Susanto \\ Program Studi Pendidikan Sejarah, FKIP Universitas Lambung Mangkurat, Banjarmasin \\ E-mail: iniherisusanto@ulm.ac.id
}

\begin{abstract}
Abstrak
Penelitian ini bertujuan untuk mengetahui keefektifan aplikasi pembelajaran yang diakses melalui mobile smartphone sebagai media pengenalan sejarah lokal masa revolusi fisik di Kalimantan Selatan. Metode kuantitatif digunakan dengan desain pre-experimental one-group pretestposttest dimana peneliti menguji efektivitas media dengan membandingkan pemahaman siswa sebelum dan sesudah diberi treatment. Subjek penelitian adalah siswa kelas XI IPS SMAN 7 Banjarmasin yang terdiri dari dua kelas dengan jumlah populasi sebanyak 57 orang. Sampel penelitian berjumlah 25 orang siswa yang diambil dari populasi menggunakan teknik sample random sampling. Instrumen penelitian yang digunakan berupa tes berbentuk pilihan ganda dengan jumlah soal 25 butir. Validitas instrumen diuji melalui korelasi product moment, sedangkan reliabilitasnya diuji menggunakan rumus alpha cronbach. Teknik analisis yang digunakan adalah analisis paired sample $t$ test dengan hipotesis $\mathrm{H}_{0}=$ tidak terjadi peningkatan dari hasil pretest ke posttest setelah diberi treatment, dan $\mathrm{H}_{1}=$ terjadi peningkatan dari hasil pretest ke posttest setelah diberi treatment. Hasil penelitian menunjukkan bahwa setelah diberi treatment dengan menggunakan media aplikasi pembelajaran, nilai posttest siswa lebih besar dibandingkan pretest dengan rata-rata posttest $(76,80)>$ pretest $(56,32)$. Melalui perhitungan statistik diketahui bahwa $-t_{\text {hitung }}(-11,058)<-t_{\text {tabel }}(-2,064)$ dengan korelasi yang bersifat kuat dan positif sebesar 0,729 yang berarti $\mathrm{H}_{1}$ diterima sehingga dapat dikatakan terjadi peningkatan pemahaman siswa setelah menggunakan aplikasi pembelajaran. Berdasarkan hasil penelitian, disimpulkan bahwa aplikasi pembelajaran berbasis mobile smartphone efektif digunakan sebagai media pengenalan sejarah lokal masa revolusi fisik di Kalimantan Selatan pada siswa kelas XI IPS SMA Negeri 7 Banjarmasin.
\end{abstract}

Kata Kunci: Sejarah Lokal, Aplikasi Pembelajaran Berbasis Mobile Smartphone

\begin{abstract}
This study aims to examine the effectiveness of a learning application that is accessed through mobile smartphones as a medium of introduction of local history during the physical revolution in South Kalimantan. Quantitative method was used with pre-experimental one-group pretestposttest design in which the researchers tested the effectiveness of the media by comparing the students' understanding before and after being treated. The subjects of the study were students of class XI IPS SMAN 7 Banjarmasin consisting of two classes with a population of 57 people. The sample of this research was 25 students taken from population using sample random sampling technique. The research instrument used in the form of multiple choice test with the number of 25 items. Instrument validity was tested through product moment correlation, while its reliability was tested using alpha cronbach formula. The analysis technique used was paired sample t test with hypothesis $\mathrm{HO}=$ no increase of pretest result to posttest after treatment, and $\mathrm{H} 1=$ increase of pretest result to posttest after given treatment. The results showed that after being treated using instructional media application, students' posttest score was greater than pretest with mean posttest $(76,80)>$ pretest $(56,32)$. Through the statistical calculation known that -thitung ($11,058)<-$ ttabel $(-2,064)$ with a strong and positive correlation of 0.729 which means $H 1$ accepted so that it can be said to occur increased understanding of students after using the application of learning. Based on the results of the study, it was concluded that the application of mobile smartphone-based learning is effectively used as a medium of introduction of local history of physical revolution in South Kalimantan in the students of class XI IPS SMA Negeri 7 Banjarmasin. Keywords: Local History, Learning Application Based on Mobile Smartphone
\end{abstract}




\section{PENDAHULUAN}

Era abad ke-21 teknologi informasi semakin berkembang dalam kehidupan masyarakat karena dianggap sebagai fasilitas untuk membantu pekerjaan. Banyak terobosan baru teknologi informasi yang tercipta di berbagai bidang. Begitu pula di bidang pendidikan, teknologi informasi seperti PC, laptop, bahkan mobile smartphone digunakan oleh pendidik maupun siswa sebagai alat penunjang pembelajaran. Di Indonesia sendiri, pembelajaran menggunakan bantuan teknologi informasi telah diterapkan. Semenjak dilakukannya pemutakhiran kurikulum dalam pendidikan Indonesia dari Kurikulum Tingkat Satuan Pendidikan (KTSP) menjadi Kurikulum $2013 \quad$ (K13) keterampilan menggunakan teknologi informasi dalam pembelajaran menjadi hal penting. Dalam K13 pembelajaran keterampilan menggunakan teknologi informasi tidak lagi menjadi mata pelajaran tersendiri seperti pada kurikulum sebelumnya, melainkan diintegrasikan ke semua mata pelajaran. Oleh karenanya pendidik maupun siswa diutamakan mampu menggunakan teknologi informasi sebagai media penunjang pembelajaran.

Fathurrohman

(2015:28)

menjelaskan bahwa terdapat beberapa komponen penting dalam pembelajaran, salah satunya adalah media. Media dapat memunculkan minat dan perhatian siswa

sehingga pembelajaran menjadi lebih efektif (Hamalik, 2009:64-67). Terlebih lagi ketika media yang digunakan beracuan teknologi informasi yang pada dasarnya mudah digunakan karena mempersiapkannya tidak rumit, lebih memungkinkan siswa belajar secara aktif, melatih kemampuan berpikir, serta secara tidak langsung meningkatkan keterampilan ICT literacy-nya (Unesco, 2002; Fryer, 2001).

Media berbasis teknologi informasi yang mulai dikembangkan adalah aplikasi pembelajaran. Aplikasi pembelajaran adalah sebuah perangkat lunak yang dirancang untuk melaksanakan perintah tertentu tergantung tujuan penggunaannya (Supriyanto, 2015; Dhanta, 2009). Aplikasi pembelajaran merupakan gagasan baru yang dapat digunakan secara mudah kapan dan dimana saja oleh pendidik maupun siswa. Mehdipour dan Zerehkafi (2013:95-96) menyebutkan beberapa kelebihan dari aplikasi pembelajaran, yaitu (1) membuat user mampu belajar kapan dan dimana saja, (2) fitur yang dimiliki terdiri atas grafik, suara, bahkan animasi, (3) pesan pembelajaran disampaikan secara fleksibel, dan (4) evaluasi hasil belajar dapat dilakukan secara mandiri oleh siswa.

Pada umumnya aplikasi
pembelajaran dapat diakses melalui
berbagai perangkat keras terutama laptop
dan mobile smartphone. Laptop yang


notabene memiliki bentuk yang kurang minimalis membuat orang jarang membawanya, lain halnya dengan mobile smartphone yang memiliki bentuk beragam dan cukup minimalis sehingga tidak jarang orang membawanya kemanapun mereka pergi. Selain itu, mobile smartphone merupakan perangkat keras yang memiliki berbagai fitur yang hampir setara dengan laptop. Mobile smartphone memiliki prosesor yang cukup tinggi, memori yang besar, dan RAM tambahan seperti PC atau laptop (Heriyanto, 2016). Beberapa keunggulan tersebut membuat orang tertarik menggunakan mobile smartphone.

Saat ini peminat mobile smartphone berkembang secara signifikan, World Bank melaporkan bahwa sekitar 6 miliar lebih penduduk dunia telah menggunakan mobile smartphone, bahkan seperempat dari jumlah tersebut memilikinya secara pribadi (Kelly \& Minges, 2012). Lembaga Riset Digital Marketing Emarketeer melaporkan khusus di Indonesia jumlah pengguna mobile smartphone terutama dikalangan remaja berkembang pesat sehingga telah diprediksi bahwa tahun 2018 mencapai lebih dari 100 juta (Wahyudi, 2015). Memiliki fitur yang hampir sama dengan PC atau laptop dan jumlah pengguna yang banyak terutama dikalangan remaja menjadi potensi besar digunakannya mobile smartphone sebagai media pembelajaran. Oleh karenanya penelitian terkait dengan penggunaan mobile smartphone menjadi perhatian utama khususnya di bidang pendidikan.

Di bidang pendidikan khususnya pembelajaran, mobile smartphone digunakan untuk membantu pendidik maupun siswa mencari berbagai informasi pelajaran. Fasilitas yang sering digunakan ialah internet. Melalui fasilitas internet, pendidik dan siswa dengan mudah mendapatkan informasi pelajaran. Fasilitas internet yang terdapat pada mobile smartphone memang berguna membantu proses pembelajaran. Namun jika ditelaah lebih mendalam sebenarnya mobile smartphone memiliki banyak fasilitas lainnya, salah satunya aplikasi pembelajaran yang dirasa mampu menunjang pembelajaran. Sebagaimana telah diuraikan oleh Mehdipour dan Zerehkafi, aplikasi pembelajaran memiliki berbagai keunggulan yang dapat membantu pendidik dan siswa dalam pembelajaran. Tidak terkecuali dalam pembelajaran sejarah. Sejarah yang merupakan kajian mengenai aktivitas manusia di masa lalu yang tidak dapat dilihat secara langsung di masa sekarang membuat mata pelajaran ini lumayan sulit untuk diajarkan. Pendidik mengalami kesulitan dalam memberikan contoh nyata dari peristiwa yang terjadi di masa lalu karena peninggalannya kebanyakan berupa benda atau artefak yang tidak bisa dibawa begitu saja untuk diperlihatkan kepada siswa. Oleh 
karenanya bantuan media sangat diperlukan dalam mengajar sejarah.

Berdasarkan uraian tersebut, maka dilakukan penelitian mengenai efektivitas penggunaan aplikasi pembelajaran berbasis mobile smartphone sebagai media pengenalan sejarah lokal masa revolusi fisik di Kalimantan Selatan pada siswa kelas XI IPS SMA Negeri 7 Banjarmasin. Selain bertujuan untuk mengetahui keefektifan aplikasi pembelajaran, penelitian ini juga dimaksudkan untuk membuktikan bahwa sejarah lokal yang jarang diajarkan kepada siswa mampu diketahui dan dipahami secara mudah oleh mereka melalui media aplikasi pembelajaran.

\section{METODE PENELITIAN}

Efektivitas penggunaan aplikasi
pembelajaran smartphone sebagai media pengenalan sejarah lokal masa revolusi fisik di Kalimantan Selatan merupakan penelitian bersifat eksperimental sehingga metode yang digunakan adalah metode kuantitatif. Subjek penelitian adalah siswa kelas XI IPS SMA Negeri 7 Banjarmasin dengan jumlah populasi sebanyak 57 orang. Pengambilan sampel penelitian menggunakan teknik sampel acak sederhana (simple random sampling). Sugiyono (2014:120) dan Noor (2011:151) menjelaskan bahwa teknik sampel acak sederhana merupakan teknik yang paling sederhana dimana sampel diambil secara acak tanpa memerhatikan strata populasi yang hanya memiliki satu ciri (homogen atau relatif homogen). Peneliti menggunakan teknik sampel acak sederhana karena populasi penelitian bersifat relatif homogen, yakni kelas XI IPS yang hanya terdiri dari dua kelas. Kemudian sampel yang telah ditentukan tersebut dibentuk menjadi kelompok tersendiri berjumlah 25 orang siswa. Kelompok siswa yang telah terbentuk diyakini mampu mewakili kelasnya masing-masing.

Desain eksperimen yang digunakan dalam penelitian adalah preexperimental one-group pretest-posttest dimana peneliti menguji efektivitas media dengan membandingkan pemahaman siswa sebelum dan sesudah diberi treatment. Sebelum diberi treatment, terlebih dahulu peneliti melakukan pretest kepada kelompok siswa yang menjadi sampel penelitian dengan tujuan untuk mengetahui pemahaman awal mereka mengenai sejarah lokal masa revolusi fisik di Kalimantan Selatan. Setelah itu, kelompok siswa tersebut diberi treatment dengan meminta mereka menggunakan aplikasi pembelajaran melalui mobile smartphone yang dimilikinya. Posttest kemudian dilakukan setelah kelompok siswa menggunakan aplikasi pembelajaran, tujuannya ialah untuk mengetahui keefektifan treatment yang diberikan kepada kelompok siswa. 


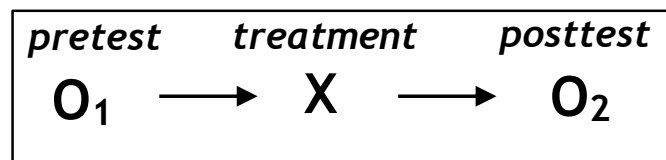

Gambar 1. Desain One Group PretestPosttest

(Sumber: Emzir, 2013:96-97; Creswell, 2013:241; Sugiyono, 2014:110)

Berdasarkan bentuk desain penelitian, pengumpulan data dilakukan menggunakan metode tes. Menurut Muliawan (2014:191), tes merupakan teknik pengumpulan data dimana subjek yang diteliti diminta mengerjakan tugas tertentu dalam bentuk tertulis, lisan, maupun praktik. Pada penelitian ini, tes yang digunakan adalah tes tertulis dengan instrumen berbentuk soal pilihan ganda (multiple choice questions) berjumlah 25 butir. Soal pilihan ganda dibuat sesuai dengan indikator pencapaiaan kompetensi dan tujuan pembelajaran yang terdapat pada kisi-kisi agar tidak menyimpang dari materi yang terintegrasi dalam aplikasi pembelajaran.

Validitas soal pilihan ganda diuji menggunakan rumus korelasi product moment dengan ketentuan apabila $r_{\text {hitung }}>$ $r_{\text {tabel }}$ maka butir soal valid, sebaliknya apabila $r_{\text {hitung }}>r_{\text {tabel }}$ maka butir soal tidak valid untuk digunakan. Hasil pengujian validitas soal yang berjumlah 25 butir menunjukkan bahwa $r_{\text {hitung }}>r_{\text {tabel }}$ sehingga dikatakan valid atau dapat digunakan untuk penelitian. Selain validitas, uji reliabilitas juga dilakukan menggunakan rumus alpa cronbach dengan ketentuan apabila $r_{11}>r_{\text {tabel }}$ maka instrumen dikatakan reliabel, sebaliknya apabila $r_{11}$ $<r_{\text {tabel }}$ maka instrumen tidak reliabel. Dari hasil pengujian reliabilitas instrumen soal pilihan ganda, semua butir soal memiliki nilai $r_{11}(0,946)>r_{\text {tabel }}(0,444)$ sehingga dinyatakan reliabel.

Teknik yang digunakan untuk menganalisis data yang diperoleh adalah uji berpasangan (paired sample $t$ test). Uji berpasangan dilakukan karena hasil tes diambil dari sampel yang sama, yaitu kelompok siswa berjumlah 25 orang dengan hipotesis $\mathrm{H}_{0}=$ tidak terjadi peningkatan dari hasil pretest ke posttest setelah diberi treatment, dan $\mathrm{H}_{1}=$ terjadi peningkatan dari hasil pretest ke posttest setelah diberi treatment. Pengambilan keputusan hasil uji berpasangan, yakni apabila $t_{\text {hitung }}>t_{\text {tabel }}$ atau $-t_{\text {hitung }}<-t_{\text {tabel }}$ maka $\mathrm{H}_{1}$ diterima, sebaliknya apabila $t_{\text {hitung }}<t_{\text {tabel }}$ atau - $t_{\text {hitung }}>-t_{\text {tabel }}$ maka $\mathrm{H}_{1}$ ditolak. Dari hasil uji berpasangan akan diketahui efektivitas penggunaan aplikasi pembelajaran berbasis mobile smartphone sebagai media pengenalan sejarah lokal masa revolusi fisik di Kalimantan Selatan kepada siswa kelas XI IPS SMA Negeri 7 Banjarmasin dengan keputusan apabila $\mathrm{H}_{1}$ diterima berarti aplikasi pembelajaran dapat dikatakan efektif, sebaliknya apabila $\mathrm{H}_{1}$ ditolak berarti media tersebut tidak efektif digunakan.

\section{HASIL DAN PEMBAHASAN}

Berhubung desain penelitian yang diadopsi yakni one group prestest- 
posttest, maka data hasil pengujian efektivitas aplikasi pembelajaran berbasis mobile smartphone pada kelompok siswa berjumlah 25 orang diperoleh melalui pretest dan posttest. Pemberian pretest dan posttest dimaksudkan untuk mengetahui seberapa besar pemahaman siswa terhadap sejarah lokal masa revolusi fisik di Kalimantan Selatan sebelum maupun sesudah diberi treatment. Data hasil pretest dan posttest tersebut sajikan dalam tabel berikut.

Tabel 1. Ringkasan Hasil Pretest dan Posttest Uji Efektivitas

\begin{tabular}{|c|c|c|c|c|c|}
\hline \multirow{2}{*}{ No } & \multirow{2}{*}{ Nama } & \multicolumn{2}{|c|}{ Nilai } & \multirow{2}{*}{ Selisih Nilai } & \multirow{2}{*}{ Peningkatan (\%) } \\
\hline & & Pretest & Posttest & & \\
\hline 1 & Siswa 1 & 76 & 88 & 12 & 15,79 \\
\hline 2 & Siswa 2 & 76 & 84 & 8 & 10,53 \\
\hline 3 & Siswa 3 & 60 & 76 & 16 & 26,67 \\
\hline 4 & Siswa 4 & 76 & 80 & 4 & 5,26 \\
\hline 5 & Siswa 5 & 60 & 72 & 12 & 20,00 \\
\hline 6 & Siswa 6 & 40 & 68 & 28 & 70,00 \\
\hline 7 & Siswa 7 & 36 & 72 & 36 & 100,00 \\
\hline 8 & Siswa 8 & 72 & 84 & 12 & 16,67 \\
\hline 9 & Siswa 9 & 56 & 76 & 20 & 35,71 \\
\hline 10 & Siswa 10 & 72 & 84 & 12 & 16,67 \\
\hline 11 & Siswa 11 & 60 & 76 & 16 & 26,67 \\
\hline 12 & Siswa 12 & 60 & 72 & 12 & 20,00 \\
\hline 13 & Siswa 13 & 48 & 68 & 20 & 41,67 \\
\hline 14 & Siswa 14 & 40 & 76 & 36 & 90,00 \\
\hline 15 & Siswa 15 & 56 & 80 & 24 & 42,86 \\
\hline 16 & Siswa 16 & 40 & 80 & 40 & 100,00 \\
\hline 17 & Siswa 17 & 44 & 76 & 32 & 72,73 \\
\hline 18 & Siswa 18 & 40 & 68 & 28 & 70,00 \\
\hline 19 & Siswa 19 & 72 & 84 & 12 & 16,67 \\
\hline 20 & Siswa 20 & 56 & 76 & 20 & 35,71 \\
\hline 21 & Siswa 21 & 52 & 72 & 20 & 38,46 \\
\hline 22 & Siswa 22 & 56 & 76 & 20 & 35,71 \\
\hline 23 & Siswa 23 & 56 & 80 & 24 & 42,86 \\
\hline 24 & Siswa 24 & 52 & 76 & 24 & 46,15 \\
\hline 25 & Siswa 25 & 52 & 76 & 24 & 46,15 \\
\hline \multicolumn{2}{|c|}{ Rata-rata } & 56,32 & 76,80 & 20,48 & 41,72 \\
\hline
\end{tabular}

Dari tabel 1 terlihat bahwa rata-rata nilai yang diperoleh melalui pretest sebesar 56,32 sedangkan rata-rata nilai hasil posttest sebesar 76,80. Rata-rata selisih perbandingan nilai pretest dan posttest sebesar 20,48 sehingga dapat dikatakan terjadi peningkatan sebesar 41,72\%. Berdasarkan hasil pretest dan posttest, disimpulkan bahwa terjadi peningkatan pemahaman siswa terhadap sejarah lokal masa revolusi fisik di Kalimantan Selatan setelah diberi treatment berupa penggunaan aplikasi pembelajaran. Peningkatan tersebut disajikan dalam bentuk diagram berikut. 


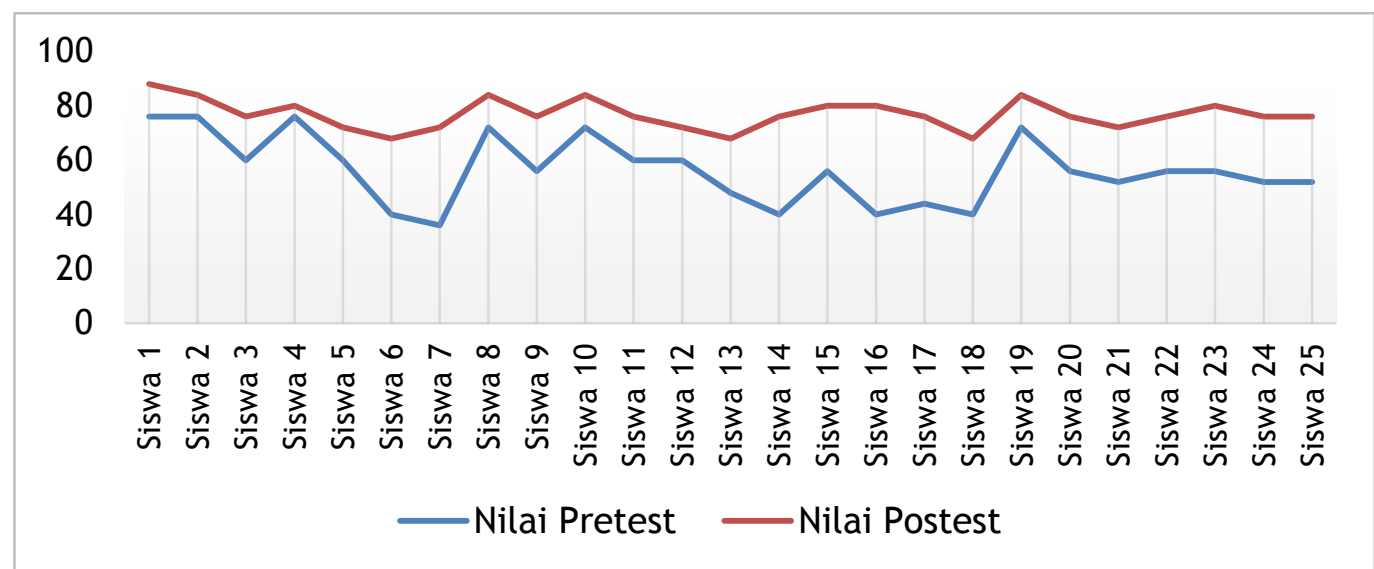

Grafik 1. Perbandingan Hasil Pretest dan Posttest Uji Efektivitas

Pembuktian uji efektivitas dilakukan posttest setelah diberi treatment, dan $\mathrm{H}_{1}$ melalui perhitungan statistik = terjadi peningkatan dari hasil pretest ke menggunakan uji berpasangan (paired posttest setelah diberi treatment. Hasil sample $t$ test) dengan hipotesis $\mathrm{H}_{0}=$ tidak perhitungan statistik disajikan dalam terjadi peningkatan dari hasil pretest ke tabel berikut.

Tabel 2. Hasil Perhitungan Statistik Uji Efektivitas

\begin{tabular}{ll|l|r|r|r}
\multicolumn{7}{c}{ Paired Samples Statistics } \\
& \multicolumn{1}{c}{ Mean } & N & Std. Deviation & Std. Error Mean \\
\hline Pair 1 & Pretest & 56.3200 & 25 & 12.43222 & 2.48644 \\
\cline { 2 - 7 } & Posttest & 76.8000 & 25 & 5.41603 & 1.08321 \\
\hline
\end{tabular}

Paired Samples Correlations

\begin{tabular}{llr|r|r} 
& N & Correlation & \multicolumn{2}{c}{ Sig. } \\
\hline Pair 1 & Pretest \& Posttest & 25 & .729 & .000 \\
\hline
\end{tabular}

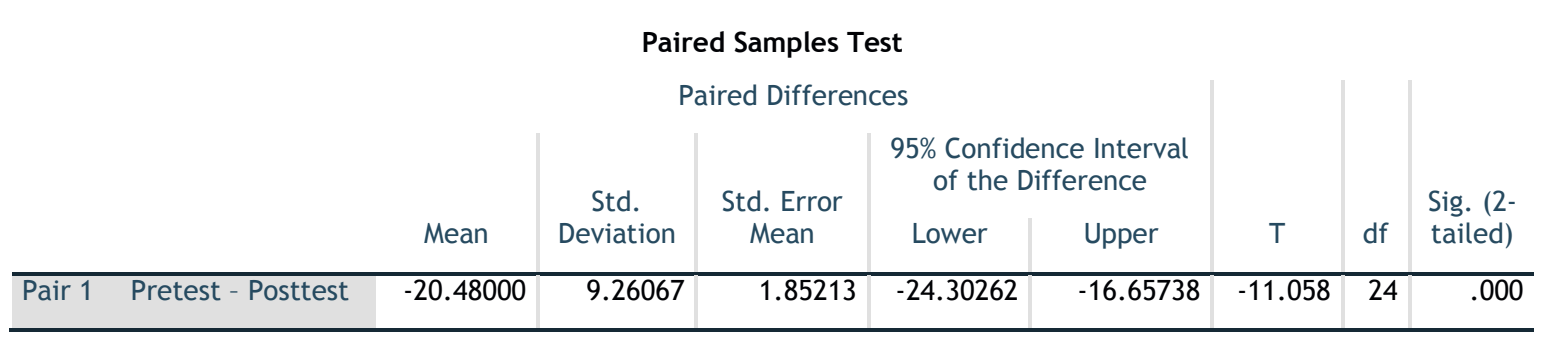

Berdasarkan hasil perhitungan statistik uji berpasangan, diketahui bahwa thitung adalah -11,058 dan $t_{\text {tabel(sign=0,000) }}$ dengan df sebesar 24 adalah 2,064. Perbandingan antara $t_{\text {hitung }}$ dan $t_{\text {tabel }}$ yakni - $t_{\text {hitung }}(-11,058)<-t_{\text {tabel }}(-2,064)$ dengan nilai probabilitas (sig.) 0,00 lebih kecil dari 0,05. Dari perbadingan tersebut diambil keputusan bahwa $\mathrm{H}_{1}$ diterima dan $\mathrm{H}_{0}$ ditolak, ini berarti terjadi peningkatan dari hasil pretest ke posttest setelah diberi treatment sehingga dapat 
dikatakan bahwa aplikasi pembelajaran berbasis mobile smartphone efektif digunakan sebagai media pengenalan sejarah lokal masa revolusi fisik di Kalimantan Selatan pada siswa kelas XI IPS SMA Negeri 7 Banjarmasin. Angka korelasi perhitungan sebesar 0,729 sehingga keputusan bersifat kuat dan positif.

Aplikasi pembelajaran merupakan terobosan baru media belajar yang memberikan kebebasan mutlak bagi siswa mengoperasikannya. Pada dasarnya, aplikasi pembelajaran memiliki manfaat untuk memudahkan siswa dalam mempelajari materi tertentu. Hake (dalam Cahyadi, 2003) menjelaskan bahwa aplikasi yang diprogram sebagai media penunjang mampu membuat pembelajaran menjadi lebih efektif tergantung tujuan penggunaannya. Dalam penelitian ini, tujuan digunakannya aplikasi pembelajaran adalah untuk mengenalkan sejarah lokal masa revolusi fisik di Kalimantan Selatan. Sejarah lokal merupakan bagian penting dalam rangkaian sejarah nasional. Kartodirdjo (dalam Syaharuddin, 2015:30) mengatakan bahwa hal-hal ditingkat nasional seringkali kurang dipahami dengan baik karena tidak lebih dahulu memahami peristiwa ditingkat lokal. Halhal ditingkat nasional biasanya memiliki cakupan yang sangat luas sehingga menggambarkan pola dan masalah secara umum, sedangkan secara konkret hal tersebut baru dapat diketahui melalui gambaran peristiwa ditingkat lokal.

Selama ini cakupan sejarah yang diajarkan kepada siswa hanya pengetahuan mengenai peritiwaperistiwa ditingkat nasional. Materimateri mengenai peristiwa lokal jarang diajarkan dan sangat sedikit tertera dalam buku-buku pelajaran sehingga minim diketahui oleh siswa. Waktu untuk mengajarkan sejarah lokal juga hampir tidak tersedia. Padahal peristiwa lokal tidak kalah penting karena menggambarkan kejadian masa lalu pada wilayah dimana siswa tinggal. Siswa yang diajarkan sejarah lokal akan lebih memahami lingkungannya sendiri, kreatif dan inovatif dalam mengembangkan sesuatu menyangkut daerahnya, serta menumbuhkan rasa cinta terhadap tanah air (Widja, 1989).

Melalui media aplikasi pembelajaran, siswa dapat dengan mudah mempelajari materi sejarah lokal, salah satunya mengenai masa revolusi fisik di Kalimantan Selatan. Aplikasi pembelajaran dirancang agar digunakan secara mandiri oleh siswa kapan dan dimana saja melalui mobile smartphone yang dimilikinya. Dengan begitu keterbatasan ruang dan waktu untuk mempelajari sejarah lokal dapat teratasi.

$$
\text { Dale (dalam Asyhar, 2012:49) }
$$
menyebutkan bahwa hal paling kongkret bagi siswa mempelajari sesuatu menggunakan media adalah pengalaman 
langsung melalui berbagai alat indera yang dimilikinya. Ketika media yang digunakan mampu merangsang berbagai alat indera siswa dalam menerima dan mengolah informasi, akan berimplikasi pada semakin besarnya kemungkinan informasi tersebut dapat dipahaminya. Aplikasi pembelajaran memang dirancang untuk dioperasikan oleh siswa menggunakan tangan yang notabene merupakan indera peraba. Tampilan

\section{KESIMPULAN}

Terjadi peningkatan cukup tinggi dari rata-rata nilai pretest ke posttest setelah diberi treatment berupa penggunaan aplikasi pembelajaran dengan perbandingan sebesar 20,48 atau meningkat sebesar $41,72 \%$. Selain itu, dari hasil perhitungan statistik uji berpasangan juga diketahui bahwa - thitung $_{\text {nat }}$ $(-11,058)<-t_{\text {tabel }}(-2,064)$ dengan nilai probabilitas (sig.) 0,00 lebih kecil dari 0,05 sehingga diambil keputusan $H_{1}$ diterima dan $\mathrm{H}_{0}$ ditolak dengan angka korelasi sebesar 0,729 yang berarti bersifat kuat dan positif. Dengan demikian, dapat disimpulkan bahwa aplikasi pembelajaran yang diakses melalui mobile smartphone efektif digunakan sebagai media pengenalan sejarah lokal masa revolusi fisik di Kalimantan Selatan pada siswa kelas XI IPS SMA Negeri 7 Banjarmasin. halaman dalam aplikasi pembelajaran berupa visual teks, gambar, animasi dan rekaman suara sehingga untuk memahami isi media siswa membutuhkan indera penglihatan dan pendengaran. Dengan berbagai alat indera yang dirangsang memungkinkan siswa dapat menerima dan mengolah informasi dengan lebih baik. Oleh karenanya dapat dikatakan bahwa aplikasi pembelajaran efektif digunakan oleh siswa.

\section{DAFTAR PUSTAKA}

Asyhar, Rayandra. (2012). Kreatif Mengembangkan Media Pembelajaran. Jakarta: Referensi.

Cahyadi, Veronika. (2003). Media Pendidikan: Pengertian Pengembangan dan Pemanfaatannya. Jakarta: CV Rajawali.

Creswell, John W. (2013). Research Design: Pendekatan Kualitatif, Kuantitatif, dan Mixed, terjemahan Achmad Fawaid. Yogyakarta: Pustaka Pelajar.

Dhanta, Rizky. (2009). Pengantar Ilmu Komputer. Surabaya: Penerbit Indah.

Emzir. (2013). Metodologi Penelitian Pendidikan Kuantitatif \& Kualitatifi. Jakarta: Rajawali Pers.

Fathurrohman, Muhammad. (2015). Paradima Pembelajaran Kurikulum 2013: $\quad$ Strategi Alternatif Pembelajaran di Era Global. Yogyakarta: Kalimedia.

Fryer, Wesley A. (2001). Strategy for Effective Elementary Technology 
Integration. diunduh melalui http://www.wtvi.com/teks/integr ate/tcea2001/powerpointoutline.p $\mathrm{df}$

Hamalik, Oemar. (2009). Psikologi Belajar dan Mengajar. Bandung: Sinar Baru Algesindo.

Heriyanto, Andri Puspo. (2016). Mobile Phone Forensics: Theory. Yogyakarta: CV Andi Offset.

Kelly, T. dan Minges, M. (2012). Maximizing Mobile. Diakses pada tanggal 10 Maret 2018, tersedia pada situs www.web.worldbank.org

Mehdipour, Yousef., dan Hamideh Zerehkafi. (2013). “Mobile Learning for Education: Benefits and Challenges", International Journal of Computational Engineering Researchi, Vol. 3, Issue 6, June 2013; pp. 93-101.

Noor, Juliansyah. (2011). Metodologi Penelitian: Skripsi, Tesis, Disertasi, dan Karya Ilmiah. Jakarta: Prenadamedia Group.

Sugiyono. (2010). Metode Penelitian Pendidikan: Pendekatan Kuantitatif, Kualitatif, dan R\&D. Bandung: Alfabeta.
Supriyanto, Aji. (2005). Pengantar Teknologi Informasi. Jakarta: Salemba Infotek.

Syaharuddin. (2015). "Transformasi NilaiNilai Kejuangan Masyarakat Banjar pada Periode Revolusi Fisik (19451950) di Kalimantan Selatan (Studi Etnopedagogi dalam Pengembangan Kurikulum Pendidikan IPS)" Disertasi, Bandung: Program Doktoral Pendidikan IPS Universitas Pendidikan Indonesia.

Unesco Institute for Information Technologies in Education. (2002). "Toward Policies for Integrating ICTs into Education." Moscow: HighLevel Seminar for Decision Makers and Policy-Makers.

Wahyudi, Ade. (2015). Indonesia Raksasa Teknologi Digital Asia [Majalah Online Tempo.com]. Diakses pada tanggal 27 Mei 2016, tersedia pada situs www.tempo.co/read/kolom/2015/ 10/02/2310/indonesia-raksasateknologi-digital-asia.

Widja, I Gde. (1989). Pengantar Ilmu Sejarah dalam Perspektif Pendidikan. Semarang: Satya Wacana. 